\title{
Prevalence of skin diseases and impact on quality of life in hilly region of Nepal
}

D. P. Shrestha, D. Gurung and Inger Rosdahl

\author{
Linköping University Post Print
}

\section{Tweet}

N.B.: When citing this work, cite the original article.

Original Publication:

D. P. Shrestha, D. Gurung and Inger Rosdahl, Prevalence of skin diseases and impact on quality of life in hilly region of Nepal, 2012, Institute of Medicine. Journal, (34), 3, 44-49.

Postprint available at: Linköping University Electronic Press

http://urn.kb.se/resolve?urn=urn:nbn:se:liu:diva-101086 


\title{
Prevalence of skin diseases and impact on quality of life in hilly region of Nepal
}

\author{
Shrestha D P, Gurung D, Rosdahl I \\ Institute of Medicine, Maharajgunj, Kathmandu, Nepal; Kathmandu Medical College, Sinamangal, Kathmandu, Nepal, \\ and Department of Clinical and Experimental Medicine, Linköping University, Sweden
}

Correspondance to: Shrestha DP, Institute of Medicine, Maharajgunj, Kathmandu, Nepal, phone: 97715592217

E-mail: drdpshrestha@gmail.com

\begin{abstract}
Introduction: Skin diseases (SDs) are one of the most common health problems in Nepal. The objectives of this study are to determine the prevalence of SDs and impact on quality of life (QoL) in a rural community in Nepal.

Methods: A house-to-house survey was conducted in a community with 3,207 inhabitants, to obtain socio-demographic data and identify individuals with SDs. Free examination and treatment was offered at 4 health camps. Individuals with long-standing SDs were interviewed using the Dermatology Life Quality Index (DLQI).

Results: Of 735 individuals attending the health camps, 645 (mean age 24.9 years, range 0.5 -90) had one or more SDs. The overall prevalence of SDs was $20.1 \%$ (males $18.1 \%$, females $22.5 \%$ and children $28.2 \%$ ). The most common SD categories were eczemas $(12.2 \%)$, pigment disorders $(4.1 \%)$, acne $(2.7 \%)$, urticaria $(2.4 \%)$ and moles and lumps $(1.6 \%)$. In the Nepalese culture, the DLQI question on sexuality was too direct so only $9 / 10$ questions were used. In the 75 patients who were interviewed, the mean DLQI score was 10.7 (range 7-19), indicating a large impact on QoL.

Conclusions: This population-based study shows that SDs were very common in a rural community in Nepal. The five most common SD categories comprise $77 \%$ of all SDs. Targeted training should enable health-care workers to prevent, accurately diagnose and manage these problems on site. An appropriate instrument to measure QoL adjusted to the socio-cultural norms of Nepal has to be developed.
\end{abstract}

Key words: Prevalence; Quality of life; Skin disease

\section{Introduction}

Nepal is a mountainous country on the southern slopes of the Himalayas and is divided into 3 eco-climatic regions - the high mountains in the north, the hills in the center covering the largest area and a small belt of low land, the terai, in the south. Nepal is densely populated, with a population of 26.6 million, the majority of whom live in rural areas often in remote and difficult terrain ${ }^{1}$. Despite the fact that the Ministry of Health aims to provide the same basic health care to all inhabitants, Nepal currently has a precarious and unequal health-care system, with limited access for people in rural areas.

According to the annual reports of the Ministry of Health and Population in $\mathrm{Nepal}^{2}$, skin diseases (SDs) are one of the leading causes of morbidity, with approximately $2,700,000$ and 2,680,000 visits to outpatient clinics in 2009 and 2010, i.e. the 4 th and 5 th most common reasons for consultations. Worldwide, SDs are one of the most ubiquitous health problems, affecting 1 in 5 persons in the $\mathrm{UK}^{3}$ and 1 in 3 in the $\mathrm{US}^{4}$, but there are large differences between countries, climates and cultures. The highest prevalence has been reported from developing countries and poor areas. In the mountainous region of northern India, the overall 
prevalence is $45.3 \% 5$, while, in rural Sumatra, it is $28.2 \%$ ${ }^{6}$. In Africa, reported prevalence figures vary between $11.7 \%$ in Bamako, Mali, to $48 \%$ in rural Ethiopia $7,8,9,10$. The published prevalence figures in children are also high, $32 \%$ in Kenya ${ }^{11}, 34 \%$ in Mali ${ }^{12}, 31.3 \%$ in Hong Kong ${ }^{13}$ and $38.8 \%$ in northern India ${ }^{14}$. Figures of this kind reported from various countries are difficult to compare due to differences in study design, the seasonality of certain diseases and uncertainty in terms of census statistics.

From studies conducted primarily in western countries, it is well documented that SDs have a significant impact on patient's quality of life (QoL) ${ }^{15,16}$. In Nepal, the patient's QoL is usually evaluated by the physician during consultation and is mainly based on the severity of signs and symptoms, which do not necessarily match the patient's own opinion. Most available questionnaires assessing QoL have been developed in industrialized countries and address lifestyles in the west. The most widely used is the Dermatology Life Quality Index (DLQI) ${ }^{17}$. The suffering generated by skin problems in Nepal is not only due to the high prevalence, long duration and visibility of the disease, it also depends on discrimination, local beliefs and fears, as well as a lack of awareness and the availability of dermatological care. There are no QoL instruments that have been adapted to match the socio-cultural situation in Nepal.

The prevalence of SDs combined with QoL is a strong indicator of the influence of SDs on the health status in a population. These data are essential in order to plan interventions aimed at the prevention and management of SDs and will visualize and underline the necessity to allocate resources to control these problems.

We have performed a population-based study with the objective of determining the prevalence and impact of SDs on the QoL in a rural community in the hills of central Nepal.

\section{Methods}

The study was conducted in Talku-Dudhechaur, a rural village development community (VDC) $25 \mathrm{~km}$ south of Kathmandu. This community has a population of 3,207 (1,728 of male and 1,479 of female gender. of which 838 were children, $\leq 14$ years of age) and a total of 477 households. This is a poor community with all the characteristics of a rural Nepalese community in the hills, with a mainly agriculture-based economy.

\section{Baseline household survey}

Two nurses visited all 477 households in the village, during the period March-April 2009. These nurses were trained to use a dermatology screening questionnaire, a list with the Nepalese names of the ten most commonly seen SDs: scabies, eczema and/or fungal infections, bacterial infections, pruritus, warts, loss of skin color (vitiligo/ pityriasis versicolor), urticaria, moles and birthmarks, nodules and/or cysts and acne. During the house visits, the nurses provided information on the ongoing survey and documented the name of the head of the family, main profession of the family members, number of men, women and children, individuals in the family known to have skin problems, as well as the type of skin disorders, according to the list in the dermatology screening questionnaire. The skin problems which did not correspond to the list of SDs were recorded as "other skin conditions". All these data were recorded and household members were informed about the dates and locations of dermatologic health camps, where free examination and treatment were offered.

\section{Dermatologic examination and interviews}

To increase accessibility to the health camps, 4 dermatologic health camps were run at separate locations, during a period of 2 months. All community members consulting for skin problems at the health camps were examined by one of the authors, or by one of two other dermatologists (FM \& MH) in closed rooms with sufficient privacy. All individuals had their whole body, apart from the genital areas and breasts in females, examined. Patients with skin problems in those regions were examined by a dermatologist of the same gender. The majority of diagnoses were based on the patient's history and clinical signs, but 54 patients requiring biopsies to verify the diagnosis were referred to the Tribhuvan University Teaching Hospital, Kathmandu, for treatment. After examination, we tested the applicability of the DLQI15 to measure the impact of SDs on QoL in this Nepalese community. Those with recurrent or longlasting SDs were interviewed about symptoms, feelings, daily activities, wearing clothes, social/leisure activities, sport, work/school, personal relationships, sexual activity and treatment in accordance with the DLQI questionnaire. As most villagers were barely literate, an interview method had to be used and the DLQI questions were translated into Nepalese by the dermatologists participating in the health camps. The demographic and clinical data were documented on patient record forms prepared for the study.

\section{Data analysis}

The data were entered in the SPSS 13 program and analyzed. The prevalence and the impact on QoL were calculated. Fisher's exact test (two tailed) was used for significance testing.

\section{Ethical considerations}

The study was performed according to the ethical principles 
of the Helsinki Declaration and approved by the Ethical Review Board of the Nepal Health Research Council. For the Household survey and the interviews, verbal consent was obtained. All patients were provided with free consultations and medicines.

\section{Results}

\section{Baseline survey}

The head of the families reported a total of 411 family members known to suffer from a skin problem. The baseline survey thus indicated a very low prevalence of SDs in the community, $12.8 \%$.

\section{Dermatologic examination and interviews}

In all, 735 villagers (23\% of all the inhabitants in the community) attended the health camps and they were all examined. Of them, 645 (312 of male and 333 of female gender, of which 236 were children) had one or more skin problems diagnosed. The mean age was 24.9 years (0.5-90 years). The age groups most frequently represented were 5-14 (31\%), 15-24 (26\%) and 25-34 years (15-3\%), (Figure 1).

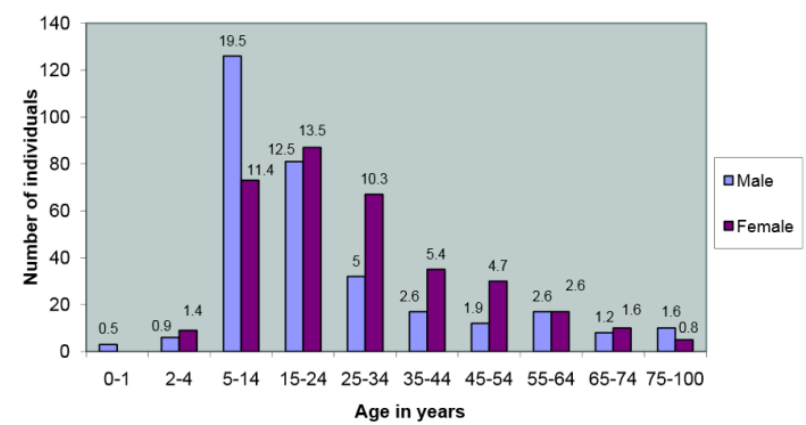

Fig 1: Age distribution of the community members with skin problem: $\%$ at the top of the columns.

Most were students/school children, followed by housewives working in the fields and farmers (Table 1).

Table 1: Occupation of the villagers with skin diseases diagnosed at the camps. n: number of individuals

$\begin{array}{ll}\text { Occupation } & \text { n (\%) } \\ \text { Farmer and Housewife } & 188(29.1) \\ \text { Farmer } & 72(11.2) \\ \text { Student/school children } & 329(51) \\ \text { Teacher } & 8(1.2) \\ \text { Mason } & 3(0.5) \\ \text { Carpenter } & 2(0.3) \\ \text { Other professions } & 43(6.7) \\ \text { Total } & 645(100.0)\end{array}$

The overall prevalence of SDs among the villagers of Talku-Dundhechaur was $20.1 \% \quad(645 / 3207)$. The prevalence was significantly higher in children $(28.2 \%)$ than adults $(17.3 \%, \mathrm{p}=<0.0001)$. There was also a significant difference between genders with females having a higher prevalence $(22.5 \%)$ than those of male $\operatorname{sex}(18.1 \%, \mathrm{p}=0.002)$.

Of the 645 patients with diagnosed SDs, 242 had two diagnoses and 73 had three. A total of 960 SDs were therefore recorded. The most common SD categories were eczemas $(12.2 \%, 392 / 3207$, followed by pigment disorders $(4.1 \%)$, acne $(2.7 \%)$, urticarial $(2.4 \%)$ and moles and lumps (1.6\%). These 5 most common categories of SDs constituted $77.2 \%$ (741/960) of all SDs diagnosed. Regarding single SDs, the most common was pityriasis alba (4\%), followed by chronic hand and foot eczema $(3.1 \%)$, melisma (2.9\%), acne vulgaris (2.4\%) and polymorphic light eruption (1.3\%), (Table 2 ).

Table 2: Skin diseases and prevalence. n: number of individuals with skin problem, total population: 3207

\begin{tabular}{lcc} 
Diagnoses & n & Prevalence \\
Eczemas & 392 & 12.2 \\
P.Alba & 131 & 4.1 \\
Chronic hand \& foot eczema & 101 & 3.1 \\
Polymorphic light eruption & 42 & 1.3 \\
Irritant contact dermatitis & 23 & 0.7 \\
Other Eczemas & 95 & 3 \\
Pigment disorders & 133 & 4.1 \\
Melasma & 92 & 2.9 \\
Vitiligo & 9 & 0.3 \\
Other pigment disorders & 32 & 1 \\
Acne & 85 & 2.7 \\
Acne grade 1 & 41 & 1.3 \\
Acne grade 2 & 22 & 0.7 \\
Acne grade 3 & 12 & 0.4 \\
Other acnes & 10 & 0.3 \\
Urticaria & 79 & 2.5 \\
Papularurticaria & 40 & 1.2 \\
Urticaria & 39 & 1.2 \\
Moles and lumps & 52 & 1.6 \\
Melanocytic nevi & 26 & 0.8 \\
Skin tags & 13 & 0.4 \\
Other moles and lumps & 13 & 0.4 \\
Pruritus & 47 & 1.5 \\
Generalized pruritus & 39 & 1.2 \\
\hline
\end{tabular}




$\begin{array}{lcc}\text { Localized pruritus } & 8 & 0.2 \\ \text { Viral infections } & 45 & 1.4 \\ \text { Verruca vulgaris } & 24 & 0.7 \\ \text { Varicella } & 9 & 0.3 \\ \text { Other viral infections } & 12 & 0.4 \\ \text { Bacterial infections } & 37 & 1.2 \\ \text { Secondary Pyoderma } & 16 & 0.5 \\ \text { Impetigo } & 6 & 0.2 \\ \text { Other bacterial infections } & 15 & 0.5 \\ \text { Fungal infections } & 32 & 1 \\ \text { P.versicolor } & 10 & 0.3 \\ \text { Other fungal infections } & 22 & 0.7 \\ \text { Infestations- scabies } & 22 & 0.7 \\ \text { Others } & 36 & 1.1\end{array}$

A total of 95 patients were interviewed to test the applicability of the DLQI questionnaire for estimating QoL. The question on sexual activity was found to be too direct for the socio-cultural norms of Nepal and only 9 of the 10 DLQI questions could therefore be used. There were other difficulties during the interviews with some patients and a total of only 75 questionnaires in which these 9 questions had been answered could be evaluated. The mean DLQI score was $10.7 \pm 3.2$ (range 7-19), indicative of a very large impact on QoL. The highest score was obtained by the question on symptoms (mean score 2), followed by the question on feelings (mean score 1.7). Despite the difficulties with the DLQI questionnaire, it was clear that the SD categories with the greatest impact on QoL were eczemas, pigment disorders, acne, urticaria and pruritus.

\section{Discussion}

SDs are known to have a significant impact on QoL. In Nepal, skin problems are one of the most common causes of medical consultations ${ }^{2}$. To the best of our knowledge, this is the first population-based study which has determined the prevalence and impact of SDs in a rural community in Nepal. The overall prevalence of SD in this study was $20.1 \%$. As in many other studies from developing countries, children and females were more vulnerable than males ( $28 \%$. 22.5\% and 18\%respectively) $)^{11-14}$. One fifth of the inhabitants affected is a fairly high prevalence for SDs, but it is considerably lower than what has been reported

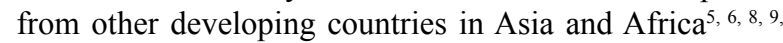
10. This difference might be due to the fact that our study was conducted during a relatively cool season and it is well known that there are large seasonal variations in the incidence of SDs, especially infectious SD, which are more common in tropical and subtropical climate zones. The number of infections and infestations were surprisingly low in the studied community, accounting for only $14.5 \%$, as compared to what has been reported from other areas. In northern India, infections and infestations accounted for $33 \%{ }^{5}$, in Sumatra $49.5 \%{ }^{6}$ and in Ethiopia $79 \%{ }^{10}$. Further, the inhabitants of Talku-Dudhechaur have ample access to water and their hygiene is therefore acceptable. These may all be factors that markedly affect both the number of infectious diseases and the overall prevalence of SDs. To clarify these issues, a similar study needs to be conducted for a longer period, a year or more.

Community members in rural areas do not consult for minor skin problems. To facilitate attendance at the medical camps, 4 camps in separate regions of the community were run in a two-month period. In spite of this, we cannot overlook the possibility that less mobile and poor residents were unable to show up. Further, it was not possible to identify and follow each individual by name and address in this rural area and the degree of overlap between the population with SD reported during the baseline survey and those showing up at the health camp could not be analyzed. The actual prevalence of $20.1 \%$ must therefore be regarded as a minimum prevalence.

A house-to-house dermatologic examination and interviews might have yielded a higher prevalence. On the other hand, $100 \%$ of the households participated in this study and $23 \%$ $(735 / 3207)$ of the total population were examined. Further, $79 \%$ more individuals than those reported to have skin problems by the head of the families were examined at the health camps and 57\% more residents than reported were diagnosed with SDs at the camp. These figures imply that the coverage of the population in this community is very high for a field survey in a rural area.

Walker et al. reported a "health-camp point prevalence" of SDs of $62.2 \%$ in the terai area, a hot and humid climate zone in Nepal. This prevalence was based on examinations of 878 individuals from 5 villages who showed up at the camps, 546 of whom were diagnosed with SDs. The corresponding camp prevalence in our study is $87.8 \%$. One reason for this difference is probably that we had already identified and invited the residents with skin problems to the camps during the baseline survey. In the study by Walker et al., there are many ambiguities that make their results difficult to interpret. They claim to have examined $39 \%$ of the population of the 5 villages, reaching a point prevalence of $24.3 \%$ (546/2249), (community prevalence). This must be a severe underestimation of the total population in the five villages. The terai is a densely populated region and, according to the 2001 census $^{19}$, the village in Bara 
district, Nepal, with the lowest population had around 2,600 inhabitants. A minimum of the population in the five villages would then be at least around 13,000. This would considerably reduce the percentage of the population examined, as well as the reliability of the prevalence figures reported.

Eczemas, including photodermatitis, were the most common SDs in our study (40.8 \%). In other studies, despite being a common skin problem, the proportion of these diagnoses was lower, $32 \%$ in northern India ${ }^{5}, 14.5 \%$ in Sumatra ${ }^{6}$ and $7 \%$ in Ethiopia ${ }^{10}$. In addition to variations in skin pigmentation and sun sensitivity between these populations, the high frequency in this study might be explained by the fact that most inhabitants were either farmers or housewives who also worked in the fields. They all walked barefoot and worked with bare hands and used no sun protection during outdoor work. The majority of them suffered from chronic irritant contact dermatitis, hand and foot eczemas, or chronic solar damage.

We experienced several difficulties when using the DLQI instrument to measure QoL in rural Nepal. Due to the high frequency of illiteracy in these areas, the DLQI had to be used as an interview instrument and questions on leisure activities, sport and clothing were found to be less relevant, while the question on sexual activity could not be applied. Further, for the Nepalese situation, it would have been more relevant if the questionnaire had covered a period longer than one week, as stipulated for the DLQI. Despite the apparent lack of conformity between the Nepalese situation and the DLQI design, we believe that we were able to obtain a reasonable impression of the very large impact SDs have on QoL in this rural community.

This study shows that SDs are common in the rural communities in the hills of Nepal and children are more affected than adults. The five most common groups of diagnosis constituted $77 \%$ of all SDs and they were also the diagnoses with the highest impact on QoL. With the limited resources available and the lack of dermatologists in rural areas, we are convinced that information and training for health-care workers will be a cost-effective way to prevent, diagnose, treat or refer these most common skin problems on site.

Since living conditions have a significant impact on the prevalence of and suffering from SDs, we are now investigating a larger number of communities in different eco-zones in Nepal. Further, there is an urgent need to develop a questionnaire adjusted to match the Nepalese situation to measure the suffering from SDs, to estimate QoL impairment over time and to evaluate disease course and treatment outcome.

\section{Acknowledgements}

We would like to thank the Nepal Health Research Council for awarding the research grant. Our gratitude also goes to Dr. Mahesh Maskey for his advice and guidance. We are grateful to Dr. Fathima Mausooma (FM) and Dr. Mohammad Haikal (MH) for assisting us with the health camps, our field assistants, Urmila Balami and Roshna Balami, and the villagers of Talku-Dudhechaur for their cooperation.

\section{References}

1. Population Census 2011: National Report. Central Bureau of Statistics, Nepal

2. Government of Nepal, Ministry of Health and Population, Department of Health Services Annual Report, 2009 and 2010. Raw Data Morbidity.

3. Rea JN et al. Skin disease in Lambeth: a community study of prevalence and use of medical care. Br J Prev Soc Med 1976; 30:107-114.

4. US Health \& Nutrition Examination Survey (HANES $-1), 1971-742$.

5. Grills N, Grills C, Spelman T et al. Prevalence survey of dermatological conditions in mountainous north India. Int J Dermatol 2012;51:579-587.

6. Saw SM, Kohl D, Adjan MR et al. A populationbased prevalence survey of skin diseases in adolescents and adults in rural Sumatra, Indonesia, 1999. Trans R Soc Trop Med Hyg 2001; 95: 384-388.

7. Mahe A, N'Diaye HT, Bobin P. The proportion of medical consultations motivated by skin diseases in the health centers of Bamako (Republic of Mali). Int J Dermatol 1997; 36: 185-186.

8. Gibbs S. Skin disease and socioeconomic conditions in rural Africa: Tanzania. Int J Dermatol 1996; 35: 633-639.

9. Satimia F T, McBride S R and Leppard B. Prevalence of skin disease in rural Tanzania and factors influencing the choice of health care, modern or traditional. Arch Dermatol, 1998; 134: 1363-1366.

10. Figueroa JI, Fuller LC, Abraha A et al.Dermatology in South Western Ethopia: Rationale for a community approach. Int J Dermatol1998; 37: 752-758.

11. Schmeller W, Dzikus A. Skin diseases in children in rural Kenya: long-term results of a dermatology project within the primary health care system. Br J 
Dermatol 2001;144:118-24.

12. Mahé A, Prual A, Konate $M$ et al. Skin diseases of children in Mali: a public health problem. Trans R Soc Trop Med Hyg 1995; 89: 467-70.

13. Fung WK, Lo KK. Prevalence of skin disease among school children and adolescents in a student health service center in Hong Kong. Ped Dermatol 2000; 17 : 6: 440-446.

14. Dogra S, Kumar B. Epidemiology of Skin Diseases in School Children: A Study from Northern India. Ped Dermatol 2003; 20: 6: 470-473.

15. Finlay AY. Psychological impact of skin disease. In: Horizons in medicine 4 (Seymour CA, Heagerty AM. eds). London: McGraw- Hill., 1993; 172-179.

16. Lewis V, Finlay AW. 10 years Experience of the Dermatology Life Quality Index (DLQI). J Investig Dermatol Symp Proc 2004; 9: 169-180.

17. Finlay AY, Khan GK. Dermatology Life Quality Index (DLQI)- a simple practical measure for routine clinical use. Clin Exp Dermatol 1994; 19: 210-216.

18. Walker SL, Shah M, Hubbard VG et al. Skin disease is common in rural Nepal: results of a point prevalence study. Br J Dermatol 2008;158:334-33

19. Population Census 2001: National Report. Central Bureau of Statistics, Nepal 